\title{
LOW COORDINATED COMPOUNDS OF GERMANIUM, TIN, AND LEAD: SOME RECENT RESULTS
}

\author{
Manfred Weidenbruch \\ Department of Chemistry, University of Oldenburg, D-26111 Oldenburg, Germany
}

\begin{abstract}
The reactions of a diarylgermylene with 1,3-diynes furnished the acetylene-linked bis(germaethenes) as the first molecules with conjugated $\mathrm{Ge}-\mathrm{C}$ double bonds. Treatment of a tetraaryldigermene with lithium and subsequent reaction with an aryl bromide yielded the first tetragermabuta-1,3-diene. The conjugation between the two Ge-Ge double bond is confirmed by the electronic spectrum. The attempted synthesis of stable germasilenes by reaction of a marginally stable diaminosilylene with several diaminogermvlenes yielded novel digermenes with some unusual features. With the recent synthesis of diplumbenes, molecules with homonuclear double bonds between all Main Group 4 elements are now known.
\end{abstract}

\section{Germylenes, digermenes, germaethenes, tetragermabutadiene}

Silylenes bearing bulky substituents undergo smooth addition reactions with numerous multiple bond systems to furnish three-membered ring compounds. These molecules can often be isolated in spite of the high degree of ring strain. For example, ditert-butylsilylene - which can easily be generated trom a cyciotrisilane - reacts with several diynes to afford isolable bis(silacyclopropenes) $\mathbf{I}$. On prolonged irradiation the three-membered rings rearrange to yield the corresponding bicyclic compounds $2[1,2]$.

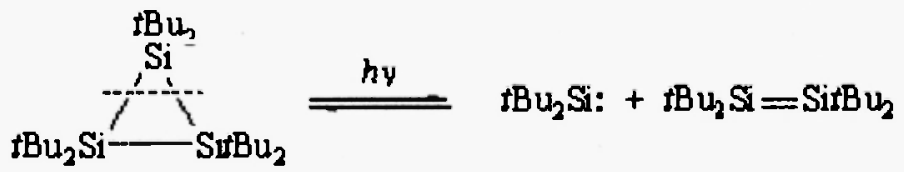

$$
\begin{aligned}
& \left(\mathrm{HBu}-\mathrm{C} \equiv \mathrm{C}-h+2 \mathrm{tBu} \mathrm{L}_{2} \mathrm{Si}: \frac{h v}{\mathrm{tBu}}\right.
\end{aligned}
$$

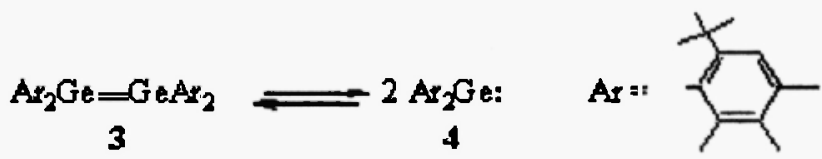

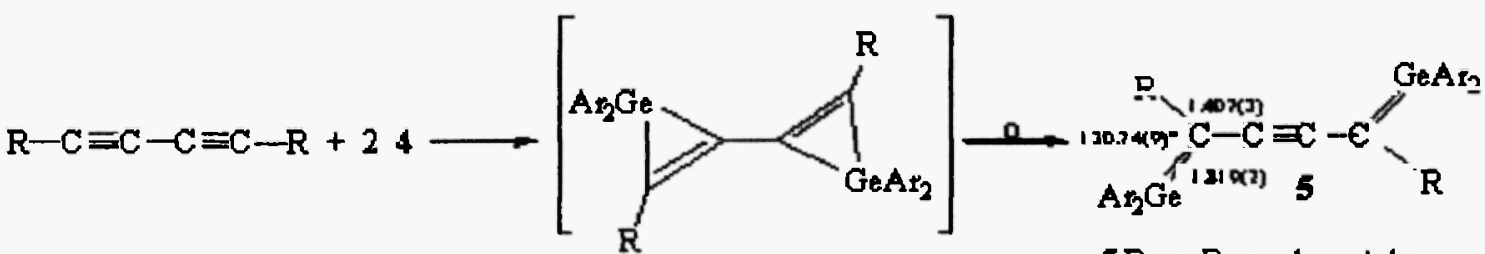

$$
\begin{aligned}
& 5 \mathrm{R}=r \mathrm{Bu}: \text { red crystals } \\
& 6 \mathrm{R}=\mathrm{C}_{6} \mathrm{H}_{5} \text { : blue-bl ack crystals }
\end{aligned}
$$

However, the reactions of germylenes with 1,3-diynes proceed differently. Some years ago we isolated the tetraaryldigermene 3 that was found to have a planar 
environment of its substituents. This digermene is stable in the solid state but, in solution, it dissociates almost completely into the germylene molecules 4 [3].

Reactions of diynes with this diarylgermylene furnished the acetylene-linked bis(germaethenes) 5 and 6 . These are the first molecules to possess conjugated germaniumcarbon double bonds [4]. The structures of the two examples of this system do not provide any information about a possible conjugation between the multiple bonds. Thus, the germanium-carbon bond lengths are in the same range as those of simple germenes [5-81. The electronic spectra are more informative. The dark red solution of the dibutylsubstituted compound 5 shows a absorption band at longest wavelength of $518 \mathrm{~nm}$ which is bathochromically shifted by about $100 \mathrm{~nm}$ in comparison to those in the yellow or orange solutions of germaethenes. The dark blue solution of the diaryl analogue 6 displays a longest wavelength absorption at $595 \mathrm{~nm}$ and thus is strongly suggestive of conjugation of the two double bonds [4].

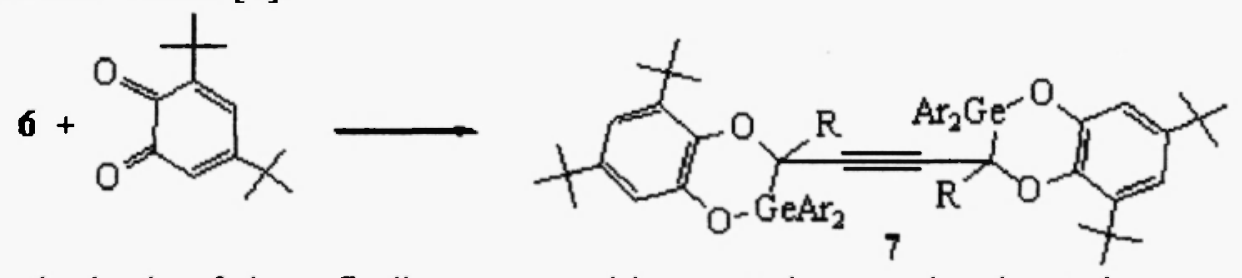

On the basis of these findings we could expect these molecules to be more reactive than the corresponding simple germaethenes. However, the opposite is true. These compounds did not react with alkynes, phosphaalkynes, and other multiply bonded compounds, species that had been successfully employed to characterise the simple germaethenes [9]. Surprisingly, the trapping reaction or 6 with an ortho-benzoquinone proceeded smoothly to yield the sterically extremely congested two-fold [2+4] cycloaddition product 7. The X-ray structure analysis of this cycloadduct clearly demonstrates the steric crowding within this molecule [10].

The unusual reaction behaviour of the diarylgermylene 4 is also reflected in attempted cycloadditions to phosphaalkynes. A couple of years ago, we had found that ditert-butylsilylene adds cleanly across the phosphorus-carbon triple bond to provide threemembered rings with a phosphorus-carbon double bond 8 [11]. Later on, Cowley showed that a dialkylgermylene, first prepared by Lappert $[12,13]$, also furnished the corresponding three-membered ring [14].<smiles></smiles>

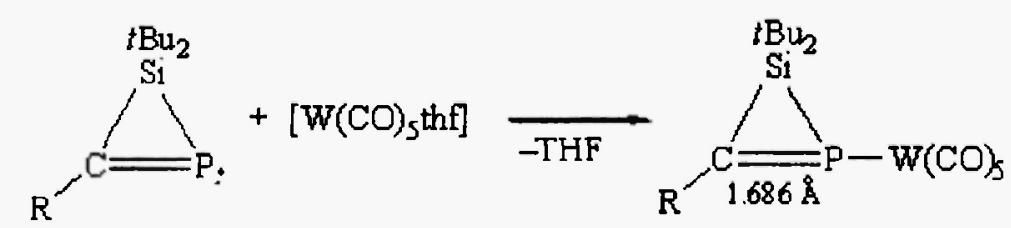

The reaction of the diarylgermylene with tert-butylphosphaalkyne proceeded differently and gave orange crystals of a product that was identified as a germadiphosphacyclobutene with an additional exocyclic germanium/carbon double bond 9 . 


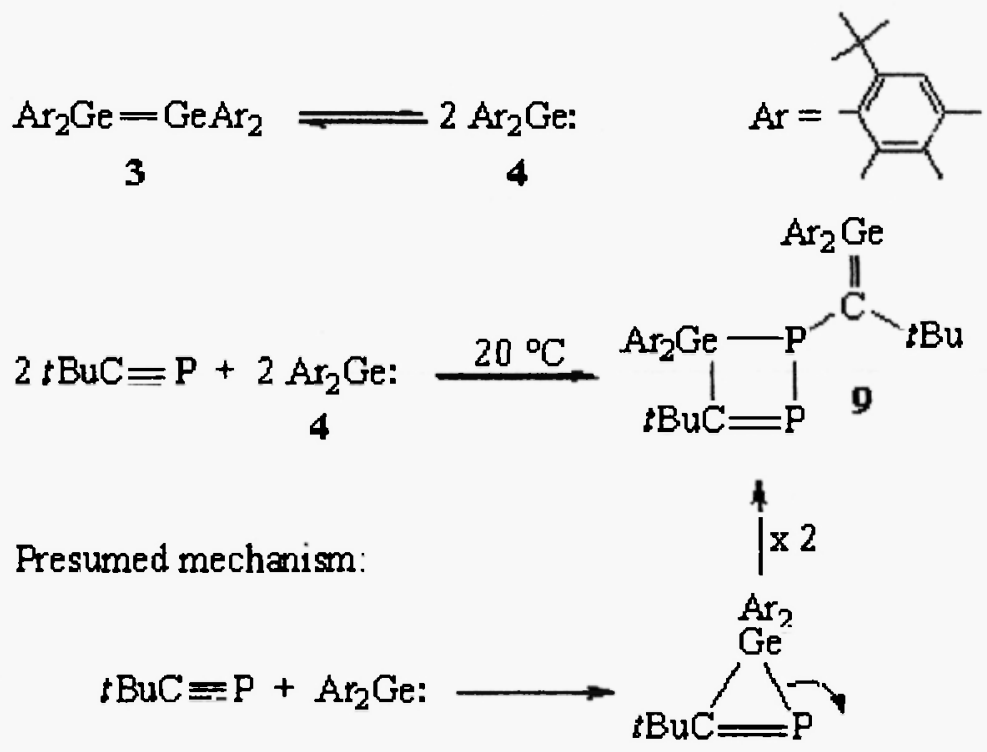

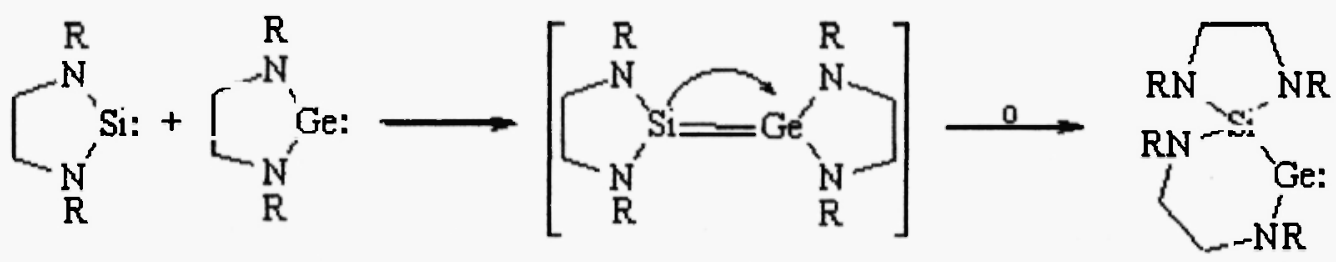

$\mathrm{R}=\mathrm{CMe}_{3}$

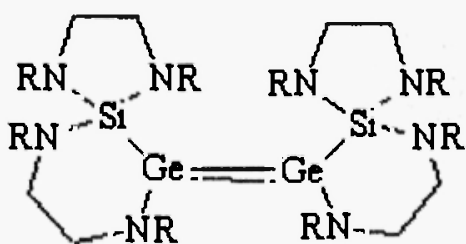

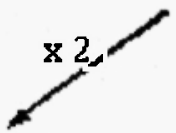

10

The unexpected formation of this molecule is unprecedented in the chemistry of phosphaalkynes and carbenes or their heavier homologues. In analogy to the formation of the acetylene-coupled bis(germaethenes), we may assume in this case that the reaction sequence is again initiated by the addition of the germylene to the phosphaalkyne to afford a tnree-membered ring system. Subsequent opening of the probably weak germaniumphosphorus single bond and dimerisation of the resulting intermediates would then yield the compound rinally isolated [15].

Wnile disilenes and digermenes are now well-known molecules, compounds with a silicon-germanium double bond were unknown until very recently, when Sekiguchi et al. prepared the first thermally stable ring compound containing this structural unit [16]. As an alternative route to a stable germasilene, we examined the reactions between several silylenes and germylenes. However, no reaction was observed in the majority of cases. The exception is the reaction of the marginally stable, saturated silylene, first prepared by West and Denk [17], with the similarly constructed germylene, first obtained by Herrmann et al. [18], which involves an unusual reaction sequence. Upon mixing the colourless solutions of these two components, a deep-red coloration occured, which is indicative of a rapid reaction between these two molecules. The X-ray structure analysis of the red crystals isolated from the reaction revealed that, instead of the expected germasilene, the digermene 10 with a number of unusual details had been formed. The germanium-germanium bond length is considerable longer than those of all known digermenes. Equally unusual are the trans-bent angles of $42^{\circ}$ which exceed all previously observed bending angles ranging from 6 to $36^{\circ}$. At present, we can only speculate on the route of formation of this 
digermene. A feasible first step is the formation of a loose adduct between the starting materials, which then furnishes a germylene by a germasilene/germylene rearrangement. Dimerisation of this germylene would then produce me isolated cls-digermene 10 [19].

Recently, West et al. showed that the marginally stable diaminosilylene undergoes a similar type of reaction to form red crystals of a diaminodisilyldisilene which possesses the longest $\mathrm{Si}-\mathrm{Si}$ double bond length and the largest trans-bending angles of all known disilenes [20].

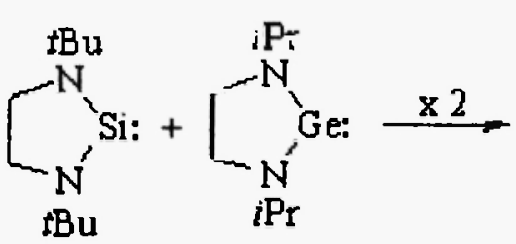

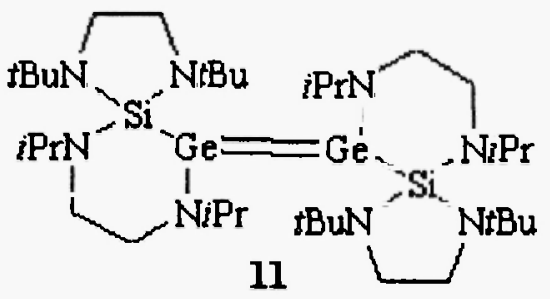
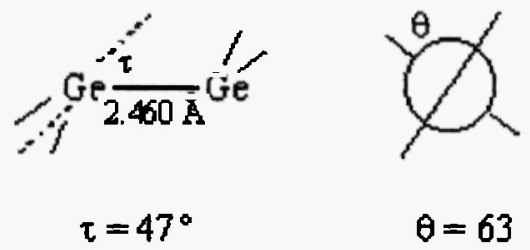

In order to further characterise this unusual bonding situations we have varied the substituents at the nitrogen atoms of the diaminogermylene. Reaction of the diisopropyl derivative with the marginally stable disilene led to an immediate coloration of the formerly colourless solutions. An X-ray structure analysis of the isolated violet crystals revealed some noteworthy features. In this case the digermene 11 adopts the trans configuration. Again, the germanium-germanium double bond is exceptionally elongated and even slightly exceeds the values observed in digermanes with a germaniumgermanium single bond. The twisting about the double bond of $63^{\circ}$ is much larger than all other angles of this type observed to date. Furthermore, the trans-bending of $47^{\circ}$ even exceeds the corresponding angle in the di-tert-butyl substituted digermene[21].

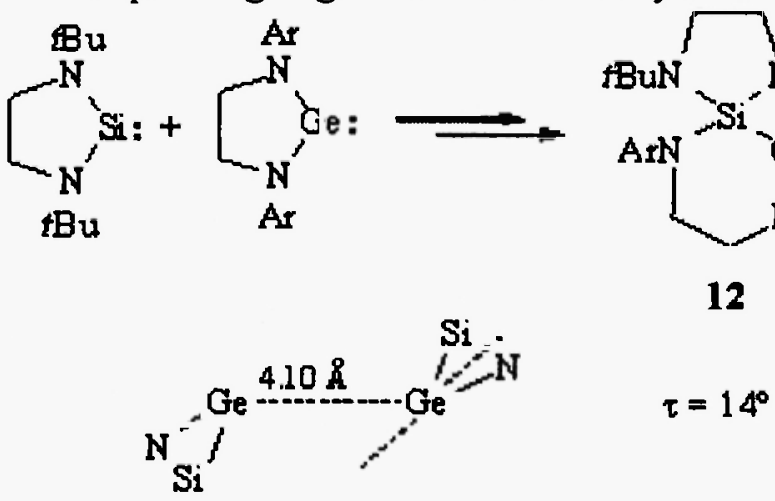

Replacement of the alkyl groups at the nitrogen atoms of the diaminogermylene by aryl groups and reaction of this germylene with the same silylene as in the reactions mentioned above gave another unexpected result. The dark red crystals, isolated in quantitative yield, proved to be the novel aminosilylgermylene 12. The separation between the germanium atoms of neighbouring germylene molecules of $410 \mathrm{pm}$ is to large for a bonding interaction. However, a contact of these germanium atoms cannot be excluded, because there is a centre of symmetry which lies at the mid-point of a line joining the two germanium atoms. Another characteristic feature is the trans-bending angle of the substituents, which with a value of $14^{\circ}$ is in the typical range for digermenes. Although the Ge-Ge contacts in this compound certainly do not represent a bond in the usual sense, they may be considered as weak dispersive forces between these atoms [21]. 
These examples clearly demonstrate that the germanium-germanium double bond is weak and can easily be elongated or twisted. This posed the question as to whether a compound with conjugated germanium-germanium double bonds could be prepared.

$$
\begin{aligned}
& \mathrm{R}_{2} \mathrm{Si}=\mathrm{SiR}_{2}+2 \mathrm{~L} \frac{\mathrm{DME}}{-\mathrm{LiR}}-\mathrm{R}_{2} \mathrm{Si}=\mathrm{Si}>_{\mathrm{Li}}^{\mathrm{R}} \frac{\mathrm{MesBr}}{-\mathrm{LMes}} \mathrm{R}_{2} \mathrm{Si}=\mathrm{Si}{ }_{\mathrm{Br}}^{\mathrm{R}}
\end{aligned}
$$

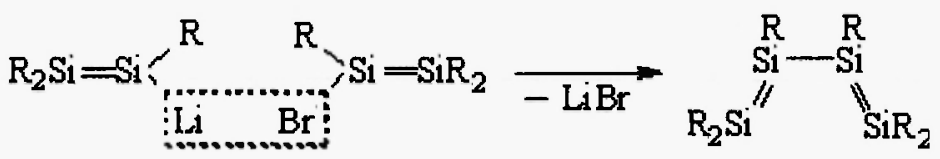

Some years ago we obtained the first and as yet only molecule with conjugated silicon-silicon double bonds. This tetrasilabutadiene was prepared by the following route. A tetraaryldisilene was treated with lithium to give the putative disilenyllithium species. In the second step of the sequence mesityl bromide was added to form the bromodisilene. Intermolecular cleavage of lithium bromide from the two intermediates then furnished the tetrasilabutadiene in an acceptable yield. The electronic spectrum of this compound clearly reveals the conjugation between the two double bonds. The longest wavelength absorption of the dark red solution is bathochromically shifted by approximately $100 \mathrm{~nm}$ in comparison to those of simple disilenes with a similar substitution pattern [22].

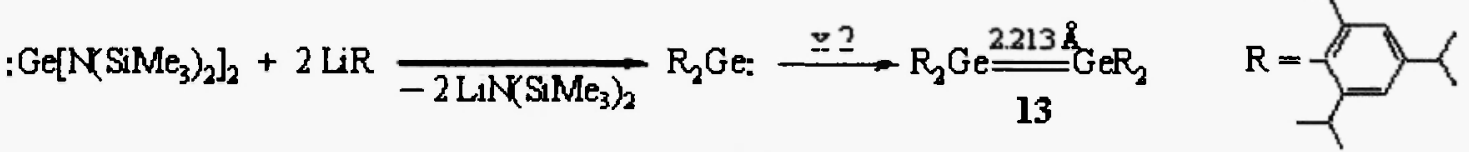

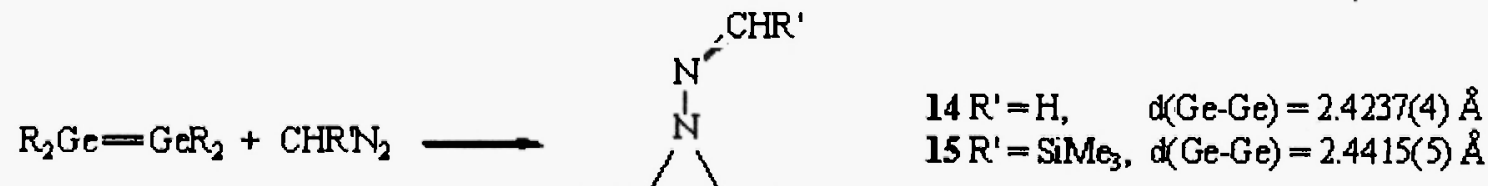

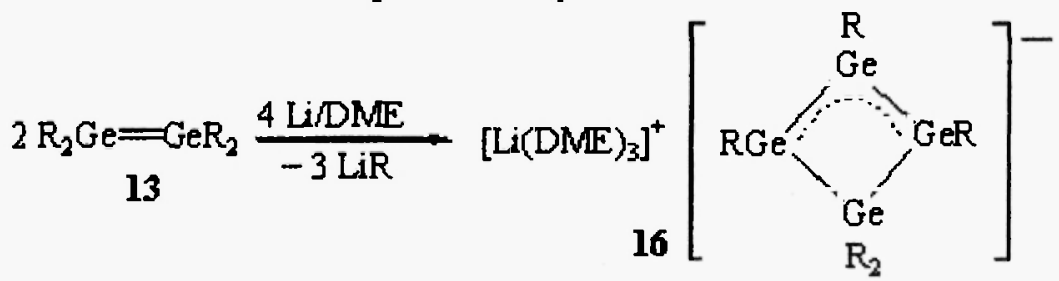<smiles>[R]c1c(C(C)C)cc(C(C)C)cc1C(C)C</smiles>

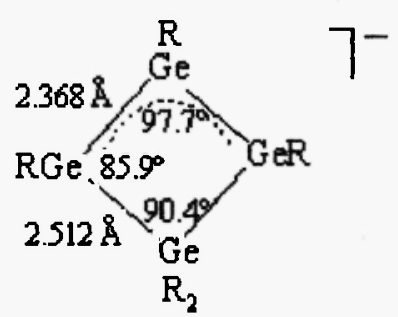

For the proposed synthesis of a tetragermabutadiene we needed a digermene which is easily accessible in a good yield and which also retains its structural integrity in solution. The tetraaryldigermene $\mathbf{1 3}$ fulfils the latter condition, however, up to now this compound was only accessible in a low yield from a multistage procedure $[23,24]$. The reaction of a germanium amide with the appropriate aryllithium compound afforded this digermene in one step and in an acceptable yield of $67 \%$. The stability of this molecule in solution was confirmed, among others, by its cycloaddition reactions with diazomethane and its trimethylsilyl derivative, from which the novel three-membered ring systems 14 and 15 composed of two germanium atoms and a nitrogen atom were isolated in high yields [25]. 
For the attempted preparation of a tetragermabutadiene, we started the reaction sequence by treatment or the tetraaryldigermene 13 with excess lithium. However, the heterogeneous reaction between these two components did not afford the digermenyllithium compound, but instead we obtained a dark-red solid which, owing to its insolubility and low volatility, could only be characterised by an X-ray structure analysis.

In accordance with the observed properties, we found the ionic compound 16 containing an allyl-like unit of three germanium atoms as part of a four-membered ring. Within this planar ring, the germanium-germanium multiple bonds differ substantially in length from the germanium-germanium single bonds [26]. The bond type in the anion is unusual to germanium chemistry and can best be compared to the acyclic anion obtained by Power from the reductive cleavage of a cyclotrigermyl radical [27].

Precisely how this anion is formed is unclear, since it involves not only the cleavage of germanium-carbon bonds in the starting digermenene, but also the formation of Ge-Gebonds.

$$
\mathrm{R}_{2} \mathrm{Ge}=\mathrm{GeR}_{2}+2 \mathrm{Li} \underset{\mathrm{l3}}{-\mathrm{LR}}-\mathrm{R}_{2} \mathrm{Ge}=\mathrm{Ge} \underset{\mathrm{Li}}{\frac{\mathrm{R}}{-\mathrm{LBR}}}-\mathrm{R}_{2} \mathrm{Ge}=\mathrm{Ge}{ }_{\mathrm{Br}}^{\mathrm{R}}
$$<smiles>[R20]C=C([R])C([R])=C[R20]</smiles><smiles>[R]C1=C(C(C)C)C(C(C)C)C=C(C(C)C)C1</smiles>

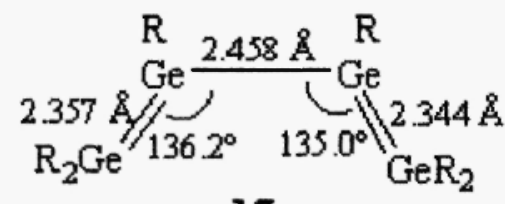

17

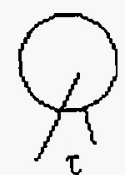

In order to eliminate all subsequent reactions of the primarily expected digermenyllithium compound, we shortened the reaction time of the digermene with lithium to such an extend that most of the digermene had reacted before the formation of the ionic compound could become the main reaction. This approach did indeed lead to the lithium compound, which by subsequent reaction with an aryl bromide presumably resulted in the bromine compound. Intermolecular lithium bromide elimination then furnished the tetragermabutadiene 17.

Similar to its silicon analogue the tetragermabutadiene adopts the s-cis form. The dihedral angle of the germanium-framework with a value of $\tau=22^{\circ}$ is notably smaller than of $51^{\circ}$ in the corresponding $\mathrm{Si}_{4}$-unit. With values of $33^{\circ}$ and $31^{\circ}$, both germaniumgermanium double bonds display a pronounced trans-bending of the substituents. The germanium-germanium double bonds are considerably elongated, although they are still in the range typical for digermenes.

Even though the crystal structure of the tetragermabutadiene reveals the existence of two double bonds, it provides only little information about the conjugation between these bonds. The electronic spectrum of the dark blue solution is more diagnostic. It shows a longest wavelength absorption at $560 \mathrm{~nm}$ which, compared to the yellow or orange digermenes, corresponds to a bathochromic shift of about 140 nanometers [26].

\section{Distannenes, stannylenes, stannaethenes}

Lappert's tetraalkyldistannene was the first compound with a homonuclear double bond between two heavier atoms of main group 4 elements to be prepared. Although this molecule was synthesised and characterised by X-ray crystallography in $1976[28,29]$, 
almost twenty years passed before two further representatives of this class of compounds could be isolated.

$$
\mathrm{SnCl}_{2}+2 \mathrm{RMgBr} \longrightarrow \frac{\mathrm{x} 2}{\text { solution }} \mathrm{R}_{2} \mathrm{Sn:}=\mathrm{R}_{2} \mathrm{Sn}=\mathrm{SnR}_{2}
$$

18

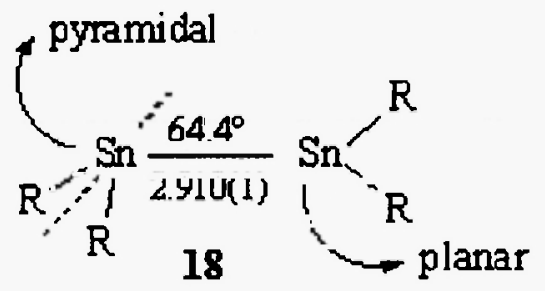<smiles>[R]c1c(C)c(C)cc(C(C)(C)C)c1C</smiles>

The tetraaryldistannene 18 has an unusual structure in the solid state. The length of the formal tin-tin double bond of $291 \mathrm{pm}$ exceeds those of the corresponding single bonds by about 13 picometers. Also unusual are the differing environments at the two tin atoms. While one tin atom has a nearly planar environment of its substituents, the other tin atom shows a pronounced trans-bending with a bending angle of $64^{\circ}$. This distannene is stable in the solid state. However, in solution it dissociates almost completely into two stannylene molecules $[30,31]$.<smiles></smiles>

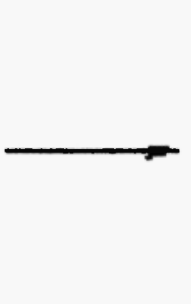<smiles>[R][R15]([R])(C)C1N(C(C)C)C(C)=C(C)N1C(C)C</smiles><smiles>[R]c1c(C(C)C)cc(C(C)C)cc1C(C)C</smiles>

$$
\begin{aligned}
d(\operatorname{Sn}-C) & =2.379 \AA \\
\theta & =68.6^{\circ}
\end{aligned}
$$<smiles>[R][R15]([R])=C1N(C(C)C)C(C)=C(C)N1C(C)C</smiles>

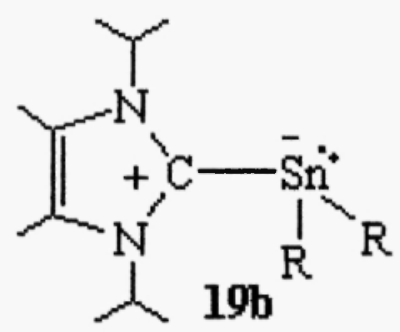

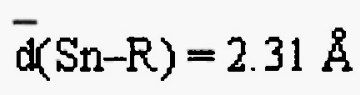

In order to simulate the bonding situation in the solid distannene 18, a nucleophilic carbene of the Arduengo type was allowed to react with a diarylstannylene. The structure of the resulting yellow crystals 19 reveals that, of the two possible forms comprising a stannene 19a on the one hand and a zwitterionic compound $19 \mathrm{~b}$ on the other hand, the latter dominates. This is corroborated by the tin-carbon oond length of $238 \mathrm{pm}$ and by the strong bending of the substituent on the tin atom with a bending angle of $69^{\circ}$ [32]. Theoretical calculations for the parent compound $\mathrm{H}_{2} \mathrm{Sn}=\mathrm{CH}_{2}$ predict a bona length of about $200 \mathrm{pm}$ and a strictly planar environment or the tin-carbon double bond [33-35].

In contrast, the stannaethene $\mathbf{2 0}$ prepared by the reaction of an electrophilic carbene with a diarylstannylene has completely planar environments of both the tin and the carbon 
atom and a tin-carbon bond length of only 203 picometers, all in good agreement with the calculated values [36].

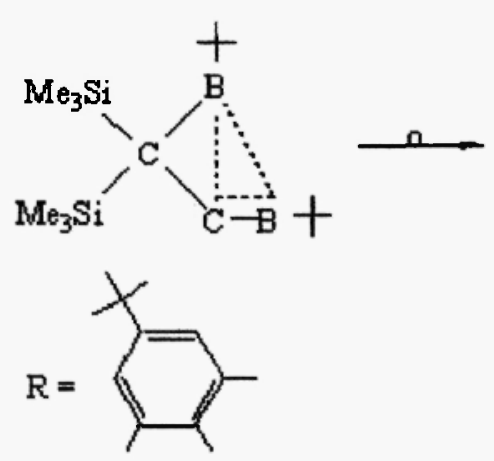

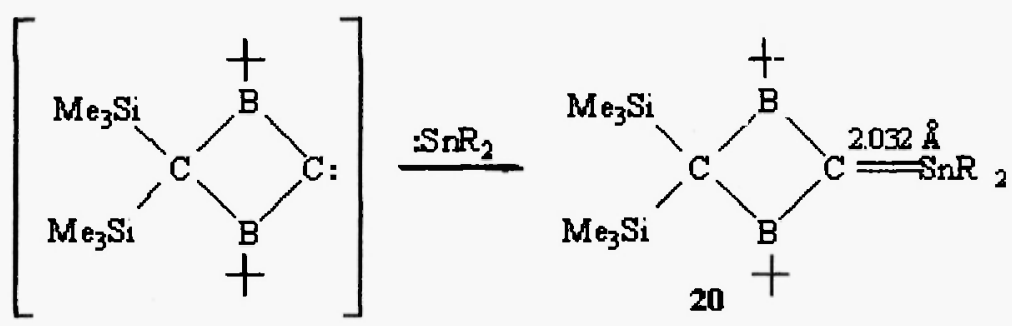

\section{Plumbylenes, diplumbenes, plumbaethenes}

Although silenes, germenes, and stannenes are now well-established, molecules with a lead-carbon double bond are still unknown. The reaction of a stable carbene with a diarylplumbylene afforded yellow crystals of compound $\mathbf{2 1}$ that is very sensitive to light and decomposes at room temperature in the solia state. The X-ray structure analysis of these crystals revealed some interesting features. The bond length between lead and the carbene carbon atom of $254 \mathrm{pm}$ is unusually long. While this carbon atom exhibits an almost planar environment, the lead atom shows a pyramidal arrangement of its substituents with a bending angle of $71^{\circ}[37]$

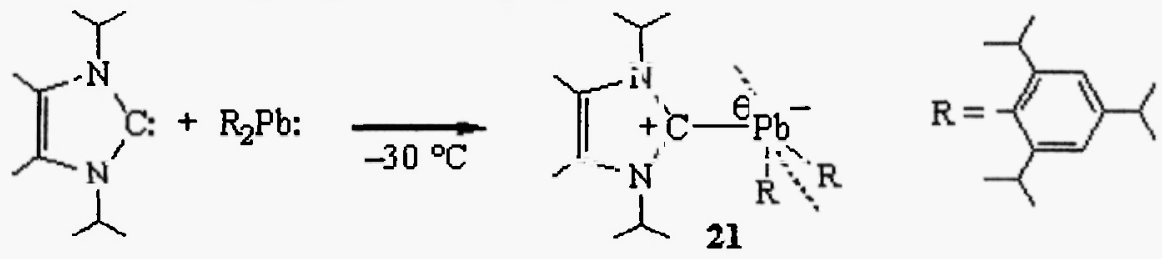

These results clearly indicate that this molecule does not possess a lead-carbon double bond, it is better described as a zwitterionic carbene-plumbylene adduct. Density functional theory calculations for the parent compound $\mathrm{H}_{2} \mathrm{~Pb}=\mathrm{CH}_{2}$ predict a lead-carbon bond length of only $204 \mathrm{pm}$ and a planar arrangement of the substituents [34].

Therefore, molecules with a lead-carbon double bond remain unknown. Reactions of an electrophilic carbene with several plumbylenes have been unsuccessful.

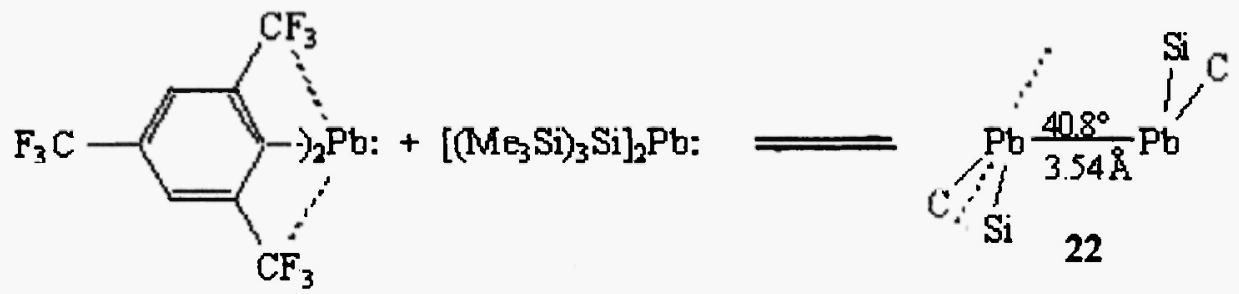<smiles>Cc1cc(C(C)(C)C)c([Pb])c(C(C)(C)[Sb])c1C</smiles>

Similar to the situation of lead-carbon double bonds, homonuclear double bonds between lead atoms were unknown until recently. A first breakthrough with regard to leadlead contacts was realised with the heteroleptic plumbylene dimer 22 prepared by 
Klinkhammer, Fässler, and Grützmacher, which shows a lead-lead separation of $354 \mathrm{pm}$ and trans-bent angles of $41^{\circ}$ [38]. Another plumbylene dimer 23 was prepared in our laboratory, which exhibits a lead-lead separation of $337 \mathrm{pm}$ and trans-bent angles of $47^{\circ}$ [39]. However, the lead-lead contacts in both compounds are still markedly larger than the bond length of between 282 and 300 pm calculated for the parent compound $\mathrm{H}_{2} \mathrm{~Pb}=\mathrm{PbH}$ $[34,39,40]$.

Since sterically less demanding aryl groups apparently favour lead-lead contacts between plumbylene molecules, we have repeated the reaction of triisopropylphenylmagnesium bromide with lead chloride at low temperature. This reaction was first described by Tokitoh, Okazaki, and their coworkers [41, 42].

$$
\begin{aligned}
& \mathrm{PbCl}_{2}+2 \operatorname{TipMgBr} \stackrel{-110^{\circ} \mathrm{C} \rightarrow 20^{\circ} \mathrm{C}}{\longrightarrow} \operatorname{Tip}_{2} \mathrm{~Pb}: \stackrel{\mathrm{x}^{2}}{=} \operatorname{Tip}_{2} \mathrm{~Pb}=\mathrm{PbTip}_{2} \\
& 24 \quad 25
\end{aligned}
$$

We obtained a violet solution of the diarylplumbylene 24 , from which red crystals of the first diplumbene 25 could be isolated. The existence of a lead-lead double bond is supported by the lead-lead bond length of $305 \mathrm{pm}$ and the trans-bent angles of 44 and $51^{\circ}$ degrees, which agree rather well with the calculated values [43].

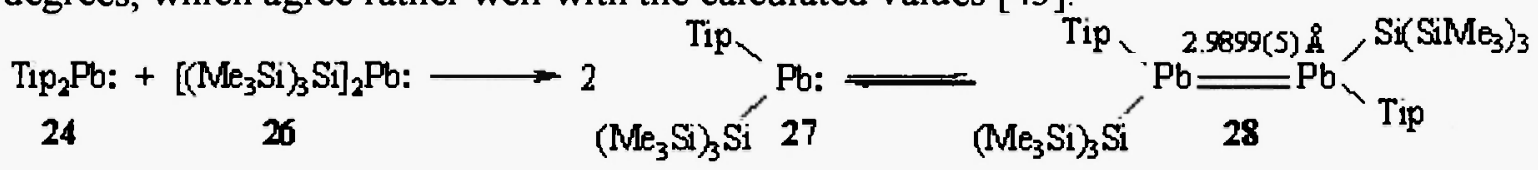

The reaction of the diarylplumbylene 24 with the disilylplumbylene 26 proceeded by rapid substituent exchange to afford a greenish-blue solution of the arylsilylplumbylene 27 from which reddish brown crystals of the heteroleptic arylsilyldiplumbene 28 were obtained. The lead-lead double bond length of $299 \mathrm{pm}$ is even shorter than that of the tetraaryldiplumbene and very close to the theoretically calculated value for the parent compound [441.

Both diplumbenes demonstrate that, in contrast to the homonuclear double bonds in the disilenes, digermenes, and distannenes where increasing bond lengths require even larger substituents for shielding, lead-lead double bonds can also be realised with smaller substituents. Therefore, we have replaced the triisopropylphenyl group by the markedly less voluminous triethylphenyl group. Reaction of the corresponding Grignard compound with lead chloride furnisned orange-red crystals of compound 29 in which, according to an $\mathrm{X}$-ray structure analysis, two diarylplumbylene molecules are linked by a magnesium dibromide molecule [45].

$$
2 \mathrm{PbCl}_{2}+4 \mathrm{RMgBr} \frac{-110^{\circ} \mathrm{C}-20^{\circ} \mathrm{C}}{-\mathrm{MgCl}_{2} / \mathrm{MgBr}_{2}}(\text { thf })_{4} \mathrm{MgBr}_{2} \cdot 2 \mathrm{PbR}_{2}
$$

29
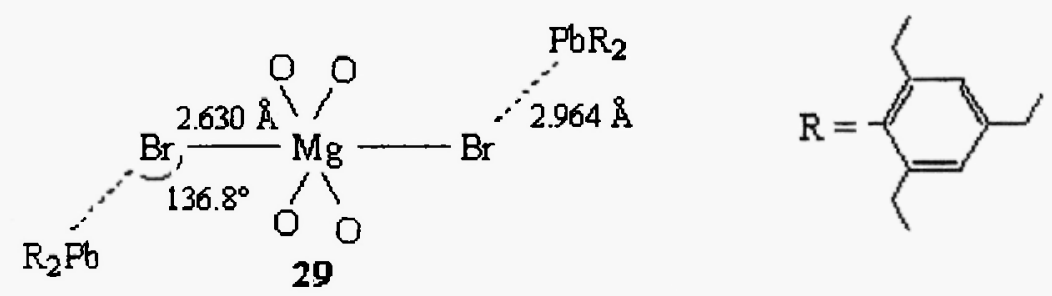

Further reduction of the steric bulk of the substituents by replacement of the triethylphenyl group by the even smaller mesityl group led to an unexpected result. 
Treatment of lead chloride with this Grignard reagent afforded black crystals of plumbylene dimer 30 which is stabilised by two magnesium bromide molecules. Worthy of note are the lead-lead separation of $335 \mathrm{pm}$ and the very large trans-bent angles of the mesityl groups of 71 degrees [441. We are currently investigating the reactions of lead halides with even smaller aryl or alkyl groups under similar reaction conditions.

$$
\mathrm{PbCl}_{2}+2 \mathrm{MesMgBr} \stackrel{-110^{\circ} \mathrm{C} \rightarrow 20^{\circ} \mathrm{C}}{\longrightarrow} \text { Black Crystals }
$$
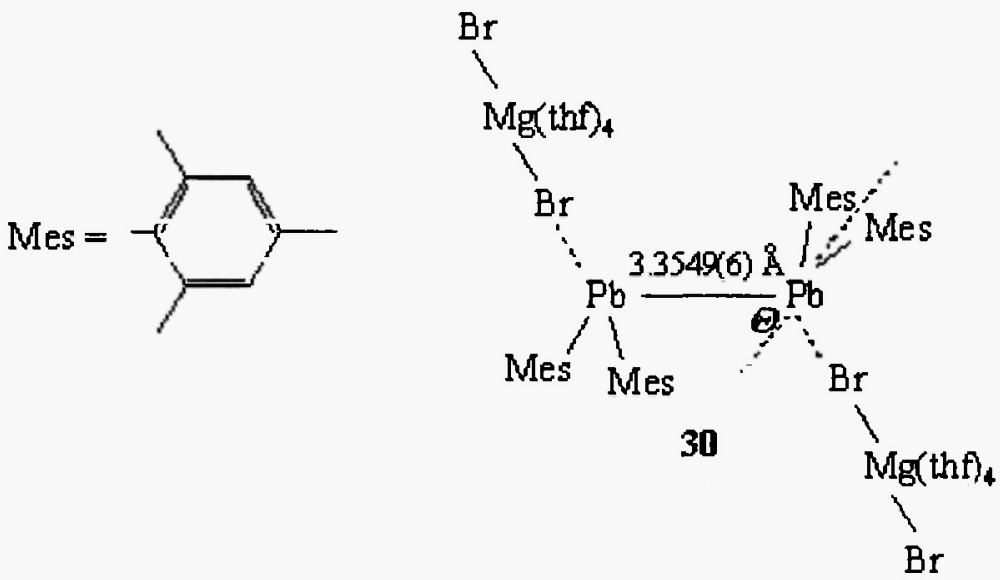

\section{Acknowledgment}

Financial support of our work by the Deutsche Forschungsgemeinschaft, the Fonds der Chemischen Industrie, and the EU (INTAS project) is gratefully acknowledged.

\section{References}

[1] D. Ostendorf, L. Kirmaier, W. Saak, H. Marsmann, M. Weidenbruch, Eur. J. Inorg، Chem. (1999) 2301.

[2] D. Ostendorf, W. Saak, M. Weidenbruch, H. Marsmann, Organometallics 19 (2000) 4938.

[3] M. Weidenbruch, M. Stürmann, H. Kilian, S. Pohl, W. Saak, Chem. Ber. 130 (1997) 735.

[4] F. Meiners, W. Saak, M. Weidenbruch, Organometallics 19 (2000) 2835.

[5] M. Lazraq, J. Escudié, C. Couret, J. Satge, M. Dräger, R. Dammel, Angew. Chem. 100 (1988), 885; Angew. Chem. Int. Ed. Engl. 27 (1988) 828.

[6] H. Meyer, G. Baum, W. Massa, A. Berndt, Angew. Chem. 99 (1987) 790; Angew. Chem. Int. Ed. Engl. 26 (1987) 798.

171 N. Tokitoh, K. Kishikawa, R. Okazaki, J. Chem. Soc., Chem. Commun. (1995) 1425.

[8] M. Stürmann, W. Saak, M. Weidenbruch, A. Berndt, D. Scheschkewitz, Heteroat. Chem. 10 (1999) 554.

[9] Reviews: (a) K. M. Baines, W. G. Stibbs, Adv. Organomet. Chem. 39 (1996) 275. (b) J. Escudie, C. Couret, H. Ranaivonjatovo, Coord. Chem. Rev. 178 - 180 (1998) 565.

[10] F. Meiners, W. Saak, M. Weidenbruch, Unpublished results.

[11] A. Schäfer, M. Weidenbruch, W. Saak, S. Pohl, Angew. Chem. 99 (1987) 806; Angew. Chem. Int. Ed. Engl. 26 (1987) 776.

[12] D. E. Goldberg, D. H. Harris, M. F. Lappert, K. M. Thomas, J. Chem. Soc., Chem. Commun. (1976) 261

[13] P. J. Davidson, D. H. Harris, M. F. Lappert, J. Chem. Soc., Dalton Trans. (1976) 2268.

[14] A. H. Cowley, S. W. Hall, C. M. Nunn, J. M. Power, J. Chem. Soc., Chem. Commun. (1988) 753 .

[15] F. Meiners, W. Saak, M. Weidenbruch, Chem. Commun. (2001) 215.

$16]$ V. Y. Lee, M. Ichinohe, A. Sekiguchi, J. Am. Chem. Soc. 122 (2000) 12604.

[17] R. West, M. Denk, Pure Appl. Chem. 68 (1996) 785. 
[18] W. A. Herrmann, M. Denk, J. Belin, W. Scherer, F.-R. Klingan, H. Bock, B. Solouki, M. Wagner, Angew. Chem. 104 (1992) 1489; Angew. Chem. Int. Ed. Engl. 31 (1992) 1485 .

[19] A. Schäfer, W. Saak, M. Weidenbruch, H. Marsmann, G. Henkel, Chem. Ber. 130 (1997) 1733

[20] T. A. Schmedake, M. Haaf, Y. Apeloig, T. Müller, S. Bukalov, R. West, J. Am. Chem. Soc. 121 (1999) 9479.

[21] A. Schäfer, W. Saak, M. Weidenbruch, Z. Anorg. Allg. Chem. 264 (1998) 1405.

[22] M. Weidenbruch, S. Willms, W. Saak, G. Henkel, Angew. Chem. 109 (1997) 2612; Angew. Chem. Int. Ed. Engl. 36 (1997) 2503.

[231 J. Park, S. A. Batcheller, S. Masamune, J. Organomet. Chem. 367 (1989) 39.

24) W. Ando, H. Itoh, T. Tsumuraya, Organometallics 8 (1989) 2759.

25 H. Schäfer, W. Saak, M. Weidenbruch, Organometallics 18 (1999) 3159

26] H. Schäfer, W. Saak, M. Weidenbruch, Angew. Chem. 112 (2000) 3847; Angew. Chem. Int. Ed. 39 (2000) 3703.

27] M. M. Olmstead, L. Pu, R. S. Simons, P. P. Power, Chem. Commun. (1997) 1595.

28] D. E. Goldberg, D. H. Harris, M. F. Lappert, K. M. Thomas, J. Chem. Soc., Chem. Commun. (1976) 261

[29] D. E. Goldberg, P. B. Hitchcock, M. F. Lappert, K. M. Thomas, A. J. Thorne, T. Fjeldberg, A. Haaland, B. E. R. Schilling, J. Chem. Soc., Dalton Trans. (1986) 2387.

[30] M. Weidenbruch, H. Kilian, K. Peters, H. G. von Schnering, H. Marsmann, Chem. Ber. 128 (1995) 983.

[31] M. A. Della Bonna, M. C. Cassani, J. M. Keates, G. A. Lawless, M. F. Lappert, M. Stürmann, M. Weidenbruch, J. Chem. Soc., Dalton Trans. (1998) 1187.

[32] A. Schäfer, M. Weidenbruch, W. Saak, S. Pohl, J. Chem. Soc., Chem. Commun. (1995) 1157

[33] T. L. Windus, M. S. Gordon, J. Am. Chem. Soc. 114 (1992) 9559.

34 H. Jacobsen, T. Ziegler, J. Am. Chem. Soc. 116 (1994) 3667.

$35^{\prime}$ K. D. Dobbs, J. W. Hehre, Organometallics 5 (1986) 2057.

[36] M. Weidenbruch, H. Kilian, H. Stürmann, S. Pohl, W. Saak, H. Marsmann, D. Steiner, A. Berndt, J. Organomet. Chem. 530 (1997) 255

[37] F. Stabenow, W. Saak, M. Weidenbruch, Chem. Commun. (1999) 1131

[38] K. W. Klinkhammer, T. F. Fässler, H. Grützmacher, Angew. Chem. 110 (1998) 114; Angew. Chem. Int. Ed. 37 (1998) 124.

[39] M. Stürmann, M. Weidenbruch, K. W. Klinkhammer, F. Lissner, H. Marsmann, Organometallics 17 (1998) 4425.

40] J. Trinquier, J. Am. Chem. Soc. 112 (1990) 2130.

41 K. Shibata, N. Tokitho, R. Okazaki, Tetrahedron Lett. 34 (1993) 1495

42] N. Tokitoh, N. Kano, K. Shibata, R. Okazaki, Organometallics 14 (1995) 3121.

[43] M. Stürmann, W. Saak, H. Marsmann, M. Weidenbruch, Angew. Chem. 111 (1999) 145; Angew. Chem. Int. Ed. 38 (1999) 187.

[44] M. Stürmann, W. Saak, K. W. Klinkhammer, M. Weidenbruch, Eur. J. Inorg، Chem. (1999) 579.

[45] M. Stürmann, W. Saak, M. Weidenbruch, Z. Anorg. Allg. Chem. 625 (1999) 705. 
